J. Lake Sci.(湖泊科学), 2008, 20(6): 802-805

http://www.jlakes.org. E-mail: jlakes@niglas.ac.cn

(C)2008 by Journal of Lake Sciences

\title{
西湖生态系统健康评价初探 ${ }^{*}$
}

\author{
卢志娟 ${ }^{1}$, 裴洪平 ${ }^{1}$, 汪 勇 ${ }^{2}$ \\ (1: 浙江大学(西溪校区)环境与资源学院环境科学系, 杭州 310028) \\ (2: 浙江省环境保护科学设计研究院, 杭州 310007)
}

摘 要: 在对湖泊生态系统健康评价研究的基础上, 提出用营养状态一综合指数法(TSI-CI)对西湖进行生态系统健康评价. 首 先选用 Chl.a、SD、TP 和 TN 四个指标用相关加权指数法进行营养状态评价, 再选择物化和生物指标无量纲化处理后计算综 合指数进行综合评价. 结果表明: 西湖生态系统健康状况与营养状态水平的变化趋势是一致的, 1-3 月健康状况相对较好, 7-9 月相对较差. 该结果客观反映了西湖的实际情况, 为西湖水质管理提供科学依据.

关键词: 生态系统健康评价; 指标; 综合指数; 杭州西湖

\section{Preliminary exploration of ecosystem health assessment for Lake West}

\author{
LU Zhijuan ${ }^{1}$, PEI Hongping ${ }^{1} \&$ WANG Yong ${ }^{2}$ \\ (1: Department of Environmental Science, College of Environment and Resource, Xixi Campus Zhejiang University, Hangzhou \\ 310028, P.R.China) \\ (2: Environmental Science Research and Design Institute of Zhejiang Province, Hangzhou 310007, P.R.China)
}

Abstract: Ecosystem health was a newly proposed concept in the world with the environment becoming serious issue and on ecosystem health assessment. A method, trophic state-comprehensive index based on researches on the lake ecosystem health had been proposed to evaluate the ecosystem health of Lake West. Firstly, four indices including Chl.a, SD, TP and TN were choosed to calculate the TSI. Secondly, undimensionalizated indices such as physical, chemistry and biology was used to calculate comprehensive index to estimate the ecosystem health state. The results showed that the health state was better in January to March than in July to September, and the trend of ecosystem health is consistent with the level of trophic state. The result reflectted the actual situation of Lake West objectively, so it can provide scientific guidance for Lake West management.

Keywords: Assessment of ecosystem health; indicators; comprehensive index; Lake West in Hangzhou

随着社会经济的发展，人们的物质生活水平不断提高，对周围的环境也提出了更高的要求，然而在 经济发展的同时，人类赖以生存的环境不断恶化，与人们生产生活息息相关的生态系统不断退化，因而 对生态系统健康的研究成为当前生态环境研究的热点之一. Costanza 提出的生态系统健康的概念得到广 泛认可 ${ }^{[1]}$, 他认为生态系统健康是指一个生态系统所具有的稳定性和可持续性, 即在时间上具有维持其 组织结构、自我调节和对胁迫恢复的能力 ${ }^{[2]}$. 根据 Costanza 等关于生态系统健康的定义, 湖泊生态系统健 康可理解为湖泊内的关键生态组分和有机组织完整且没有疾病, 受突发的自然或人为扰动后能保持原有 的功能和结构, 物质循环、能量和信息流动未受到损害, 整体功能表现出多样性、复杂性和活力 ${ }^{[3]}$. 生态 系统健康评价是环境管理的一种新方法, 其目的是确切掌握生态系统的运行状况，找出生态系统在结构 和功能上存在的问题, 采取相应手段进行调整, 实现生态系统健康发展 ${ }^{[4]}$.

指标体系法是生态系统健康评价研究的趋势, 研究至今, 学者们提出了众多评价指标, 如毛生产力指

* 国家自然科学基金项目(39170169)资助. 2007-09-28 收稿; 2008-03-04 收修改稿. 卢志娟, 女, 1983 年生, 硕士; E-mail: zhijuanlu@163.com. 
标(GEP), 生态系统压力指标, 生物完整性指标, 热力学指标, 以及包含生物、生态、社会经济和人口健 康等方面的综合指标体系等 ${ }^{[5]}$, 但由于湖泊类型多样, 地区差异显著, 未形成统一的评价指标体系. 近些 年形成的评价方法主要有: Jørgenson ${ }^{[6]}$ 提出的初步评价法, 徐福刘等 ${ }^{[7]}$ 提出的实测计算(DMM)和生态模 型(EMM)两种评价方法, 刘永等 ${ }^{[1]}$ 提出的综合健康指数法, 徐福刘等 ${ }^{[8]}$ 提出的定量评价方法一一生态系 统健康指数法等.

杭州西湖是我国著名的风景旅游湖泊，近几十年由于旅游业和城市化的迅速发展，西湖面临着以富 营养化及生态系统退化为主要特征的水质问题 ${ }^{[9]}$, 水体生态系统健康状况日益恶化, 专家学者针对富营 养化问题进行了探索研究, 取得了较大成果, 但关于西湖生态系统健康状况的研究却鲜为报道. 本文建 立以营养状态与生物和生态系统指标为基础的综合评价指数对西湖生态系统健康评价进行初步探索.

\section{1 材料与方法}

\section{1 研究材料}

西湖水域面积 $5.66 \mathrm{~km}^{2}$, 平均水深 $1.56 \mathrm{~m}$. 由于西湖为半封闭性湖泊, 水的更新程度差, 加上流域内 经济迅速发展, 致使氮、磷等营养物质大量累积, 藻类过度繁殖, 水质日益富营养化, 影响了西湖生态系 统的健康状况. 本研究选取 2001 年(12 个月)的西湖水质常规监测数据进行生态系统健康评价.

\section{2 研究方法}

湖泊生态系统是一个复杂的综合体, 必须根据湖泊的性质特征进行综合分析评价. 本研究以滇池、太 湖、巢湖等湖泊生态系统健康评价研究为借鉴, 结各西湖的实际生态环境, 运用 “营养状态指数一综合 指数法” $(T S I-C I)$ 对西湖生态系统健康状况进行评价. TSI 仅反映湖泊的营养状态, 未全面考虑生态系统 健康状况, 本文运用营养状态指数法对西湖生态系统进行初步评价, 可为综合评价提供一定的评价基础, 综合指数的计算公式为:

$$
C I=\sum_{i=1}^{m} w_{i} I_{i}
$$

式中, $C I$ 为综合指数值; $w_{i}$ 为各指标权重; $I_{i}$ 为各指标无量纲化值.

1.2.1 评价指标选择 选择评价指标是进行生态系统健康评价的关键步骤之一. 指标选择应遵循可测性、 可比性、灵敏性及综合性原则. 可测性是指所选指标的具体数值可以通过监测、统计或计算等方法获得; 可比性是指所选指标应该使得同一湖泊及不同湖泊的评价结果可以相互对比; 敏感性是指所选指标能够 比较灵敏地反映湖泊物理的或化学的或生物的或系统水平的变化; 综合性是指所选指标体系应尽可能涵 盖湖泊物理、化学、生物、生态等方面的指标, 以综合反映湖泊生态系统的状况 ${ }^{[5]}$. 依据所选评价方法及 上述原则, 本研究所选的物化指标为: 透明度 $(\mathrm{SD})$ 、溶解氧 $(\mathrm{DO})$ 、总磷 $(\mathrm{TP})$ 及总氮( $(\mathrm{TN})$; 生物指标为: 叶 绿素 $\mathrm{a}(\mathrm{Chl} . \mathrm{a})$ 、浮游植物生物量 $(\mathrm{BA})$ 、浮游动物生物量 $(\mathrm{BZ})$ 、系统能 $(E x)$ 及结构系统能 $\left(E x_{\mathrm{st}}\right)$.

1.2.2 指标计算 浮游植物生物量由叶绿素 $\mathrm{a}$ 的实测值按 $0.05 \mathrm{mg}$ 碳 $=1 \mu \mathrm{g}$ 叶绿素 $\mathrm{a}$ 换算所得; 系统能和结 构系统能是热力学指标, 已多次成功运用于生态系统健康评价. 选取浮游植物和浮游动物两项指标, 由 如下公式 ${ }^{[10]}$ 计算系统能 $(E x)$ 和结构系统能 $\left(E x_{\mathrm{st}}\right)$ :

$$
E x=\sum_{i=1}^{n} W_{i} B_{i} \quad E x_{\mathrm{st}}=\sum_{i=1}^{n} B_{i} / B_{\mathrm{t}} \times W_{i}
$$

式中, $B_{i}$ 为生态系统中第 $i$ 种生物的生物量; $B_{\mathrm{t}}$ 为系统生物总量; $W_{i}$ 为第 $i$ 种生物有机成分的权重系数, 其 中, 浮游植物和浮游动物的权重系数分别取 3.4 和 $144^{[11]}$.

1.2.3 营养状态评价方法 选取 Chl.a、SD、TP 和 TN4 个指标用相关加权营养指数法进行西湖的营养状态 评价, 计算公式 ${ }^{[12]}$ 为:

$$
\operatorname{TSI}(\Sigma)=\sum_{j=1}^{m} w_{j} \times \operatorname{TSI}(j)
$$

式中, $T S I(\Sigma)$ 为综合营养状态指数; $w_{j}$ 为第 $j$ 种参数的相关权重; $T S I(j)$ 为第 $j$ 种参数的营养状态指数, 本 
研究所选取的参数可由以下公式计算而得.

$$
\begin{aligned}
& T S I(\text { Chl.a })=10\left(2.5+\frac{0.995 \ln \text { Chl.a }}{\ln 2.5}\right) \quad T S I(T P)=10\left(9.436+\frac{1.488 \ln T P}{\ln 2.5}\right) \\
& T S I(T N)=10\left(5.453+\frac{1.694 \ln T N}{\ln 2.5}\right) \quad T S I(S D)=10\left(5.118-\frac{1.94 \ln S D}{\ln 2.5}\right)
\end{aligned}
$$

1.2.4 权重计算 综合评价过程中, 各种指标对湖泊生态系统健康状况的影响程度是不同的, 必须确定各 因子的权重. 本研究利用相关加权指数法确定因子的权重, 计算公式如下:

$$
w_{i}=\frac{r_{i j}^{2}}{\sum_{j=1}^{m} r_{i j}^{2}}
$$

式中, $w_{i}$ 为第 $i$ 个因子的权重值; $r_{i j}$ 为第 $j$ 种因子与基准参数的相关系数; $m$ 为评价因子的个数.

1.2.5 无量纲化 多指标综合评价时必须对指标进行一致化处理和无量钢化处理. 本研究首先将逆向指标 取倒数使指标一致化. 进行无量纲化方法有：“中心化”处理、“极差化”处理、“极大化”处理、“极小 化” 处理和 “均值化” 处理. 目前最常使用的是 “中心化” 法, 但该方法消除了各指标变异程度上的差 异, 不能准确反映原数据所包含的信息, 导致综合评价结果的不准确. 而均值化后保留了各指标变异程 度的信息 ${ }^{[13]}$, 适用于客观评价, 故本研究采用均值化方法进行无量纲处理.

\section{2 结果与分析}

\section{1 营养状况评价}

湖泊生态系统健康状况与富营养化程度密切相关, 富营养化程度高则生态系统健康状态相对较差 西湖的富营养化问题由来已久, 通过分析其营养状况可以初步了解西湖的健康状况. 通过 1.2.3节的计算方法, 可得西湖营养状态指数, 结果如图 1 所示:

西湖的营养状态变化与温度密切相关, 因为西湖水体中 $N 、 P$ 浓度较高, 藻类生长主要受水温的影响, 而不受 N、P 的限制. 1-3 月水温低, 叶绿素 a 含量低, 营养指数值相对较低, 健康状态相对较好; 7-11 月 营养状态指数较高, 水质较差, 说明西湖生态系统健康状况相对较差(图 1).

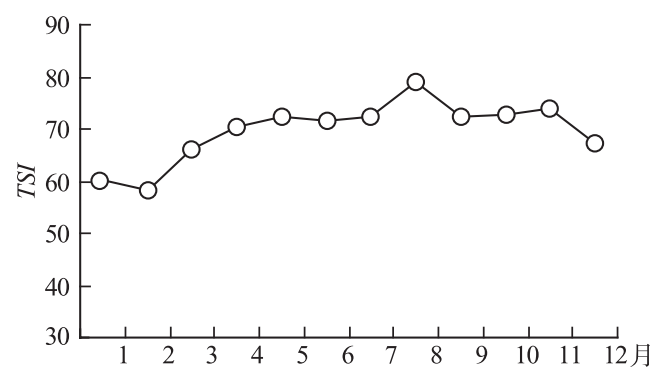

图 1 西湖营养状态指数变化趋势

Fig. 1 The trend of TSI change

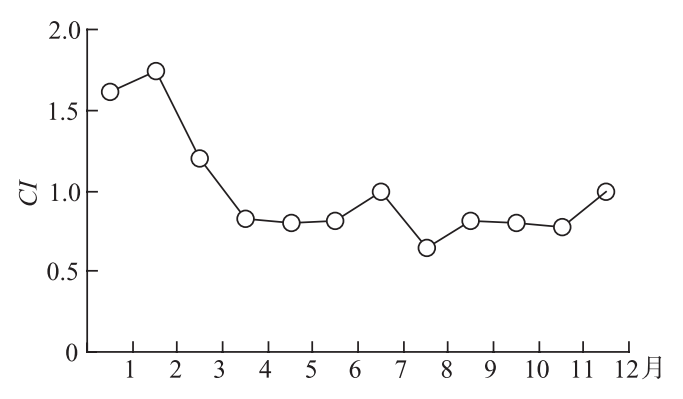

图 2 综合指数变化趋势

Fig. 2 The trend of comprehensive index change

\section{2 综合健康指数计算与分析}

2.2.1 权重计算结果 西湖是富营养化浅水湖泊, Chl.a 是水体富营养化的重要指标之一, 通过测定 Chl.a 含 量能够在一定程度上反映水质状况, 故本研究以 Chl.a 为基准参数, 根据其他各指标与 Chl.a 的相关系数 计算权重, 结果如表 1 所示.

2.2.2 综合指数计算 根据综合指数计算公式, 得出西湖生态系统健康综合指数, 健康状况变化趋势如图 2 所示. 西湖 2001 年中健康状况最好的是 2 月, 最差的是 8 月, 2-8 月(除 7 月)健康状况综合指数呈下降 趋势, 这一变化趋势与杭州的气候是密切相关的, 7 月的反常是因为此时降雨量较大, 降水的补充使湖水 
得到稀释，从而健康状态有所转好(图 2). 西湖的生态系统健康状况的变化趋势与其营养状态的变化是一 致的, 说明综合指数法对西湖生态系统评价是符合西湖实际生态环境的.

\section{表 1 各指标与 Chl.a 的相关系数及权重}

Tab.1 The relations between chlorophyll-a and other parameters and automatic measurement

\begin{tabular}{llllllllll}
\hline 参数 & Chl.a & SD & DO & TP & TN & BA & BZ & $E x$ & $E x_{\text {st }}$ \\
\hline$r_{i j}$ & 1 & -0.747 & -0.568 & 0.17 & -0.314 & 1 & 0.650 & 0.675 & 0.319 \\
$r_{i j}{ }^{2}$ & 1 & 0.558 & 0.323 & 0.029 & 0.099 & 1 & 0.423 & 0.456 & 0.102 \\
$w_{i}$ & 0.251 & 0.140 & 0.081 & 0.007 & 0.025 & 0.251 & 0.106 & 0.114 & 0.026 \\
\hline
\end{tabular}

\section{3 参考文献}

[1] 刘 永, 郭怀诚, 戴永立等. 湖泊生态系统健康评价方法研究. 环境科学学报, 2004, 24(4): 723-729.

[2] Costanza R, Norton B, Haskell B. Ecosystem health new goals for environmental management. Washington DC: Island Press, 1992: 18-24.

[3] 胡志新, 胡维平, 谷孝鸿等. 太湖湖泊生态系统健康评价. 湖泊科学, 2005, 17(3): 256-262.

[4] 米文宝, 奘新刚, 刘明丽. 宁夏沙湖水生生态系统健康评估. 生态学杂志, 2007, 26(2): 296-300.

[5] 赵榛彦, 徐福留, 詹 巍等. 湖泊生态系统健康定量评价方法. 生态学报, 2005, 25(6): 1466-1474.

[6] Jørgenson SE. Exergy and ecological buffer capacities as measures of ecosystem health. Ecosystem Health, 1995, 1(3): 150-160.

[7] Xu FL, Dawson RW, Tao S. A method for lake ecosystem health assessment: an Ecological Modeling Method and its application. Hydrobiologica, 2001, 443(1-3): 159-175.

[8] Xu FL, Zhao YZ, Zhan W et al. An ecosystem health index methodology (EHIM) for lake ecosystem health assessment. Ecological Modelling, 2005, 188: 327-339.

[9] 吴 洁, 虞左明. 西湖浮游植物的演替及富营养化治理措施的生态效应. 中国环境科学, 2001, 21(6): 540-544.

[10] Xu FL, Tao S, Dawson RW et al. Lake ecosystem health assessment: indicators and methods. Wat Res, 2001, 35(13): 3157-3167.

[11] Xu FL. Exergy and structural exergy as ecological indicators for the development state of the Lake Chaohu ecosystem. Ecological Modelling, 1997, 99: 41-49.

[12] 金相灿, 刘鸿亮, 屠清瑛等. 中国湖泊富营养化. 中国环境科学出版社, 1990: 133-135.

[13] 叶宗裕. 关于多指标综合评价中指标正向化和无量钢化方法的选择. 浙江统计, 2003, (4): 24-25. 